\title{
The study of antibiotic-sensitivity and resistance pattern of bacteria causing catheter associated urinary tract infection
}

\author{
Abha Singh, Avinashi Kujur*, Muthulakshmi M., Abha Daharwal
}

Department of Obstetrics and Gynecology, Pt. J. N. M. Medical College, Raipur, Chhattisgarh, India

Received: 13 July 2020

Accepted: 20 July 2020

\section{*Correspondence:}

Dr. Avinashi Kujur,

E-mail: avinashikujur@gmail.com

Copyright: (C) the author(s), publisher and licensee Medip Academy. This is an open-access article distributed under the terms of the Creative Commons Attribution Non-Commercial License, which permits unrestricted non-commercial use, distribution, and reproduction in any medium, provided the original work is properly cited.

\begin{abstract}
Background: present study is done to study the antibiotic-sensitivity and resistance pattern of bacteria causing catheter associated urinary tract infection. Objectives of this study were to study the bacterial etiology of CAUTI, to study the prevalence of various bacteria causing catheter associated urinary tract infection, the antibiogram (sensitivity and resistance) pattern of isolated bacteria and the percentage of asymptomatic bacteriuria in the study population.

Methods: In this prospective observational study, under aseptic precautions, urine sample was taken after 48 hours of catheterization and sent for culture and sensitivity pattern is studied.

Results: In this study 500 urine samples were cultured and its antibiotic sensitivity pattern was observed. Out of the 53 culture positive samples most the subjects had asymptomatic bacteriuria. The study gave the incidence of catheter associated urinary tract infection (CAUTI) to be $10.6 \%$ and about $9 \%$ were polymicrobial. In this study about 7 causative bacteria were isolated. Escherichia coli were the most common organism that was isolated. On studying the antibiotic susceptibility pattern of each isolate, it has been observed that all of them are multidrug resistant and the sensitivity pattern is migrating towards higher antibiotics.

Conclusions: Empirical use of antibiotics must be avoided and antibiotics must be used only after sensitivity testing. This will help in selection of the appropriate antibiotic for therapeutic use and prevent indiscriminate and irrational use of antibiotics. This will also improve the cost efficiency and decrease the duration of hospital stay.
\end{abstract}

Keywords: Antibiotic resistance, Antibiotic sensitivity, Catheter associated urinary tract infections

\section{INTRODUCTION}

According to $\mathrm{WHO}$, at any time, up to $7 \%$ of patients in developed and $10 \%$ in developing countries will acquire at least one hospital acquired infections. Some of these infections include catheter associated bloodstream infection, ventilator associated pneumonia, surgical site infection, catheter associated urinary tract infection (CAUTI). Urinary tract infections (UTIs) are the fourth most common type of healthcare-associated infection, with an estimated 93,300 UTIs in Intensive Care Units in 2011. ${ }^{1}$ Among UTIs acquired in the hospital approximately $75 \%$ are associated with a urinary catheter. ${ }^{1}$
The risk factors for catheter associated urinary tract infections can be of two types, modifiable and nonmodifiable. The total duration of catheterization, taking steps to adhere to aseptic catheter care, inserting catheter outside the operating room, a breach in the closed system of catheter drainage are few of the modifiable risk factors, which if controlled can prevent it from happening. ${ }^{2}$ Whenever CAUTI is undiagnosed or untreated, it can lead to complications such as cystitis, pyelonephritis, gram-negative bacteraemia, endocarditis, vertebral osteomyelitis, septic arthritis, endophthalmitis and meningitis in patients. Complications associated with CAUTI cause discomfort to the patient, prolonged hospital stay and increased cost. Bacteriuria also leads 
unnecessary antimicrobial use and urinary drainage systems can be reservoirs for multidrug-resistant bacteria and source of transmission to other patients.

\section{METHODS}

After written consent, women who were admitted in obstetric ward and in need of catheterization, were included in the study. Under aseptic precautions, first urine sample was taken at the time of catheterization and sent for culture and sensitivity and to rule out pre-existing urinary tract infections. Women were managed with antibiotics as per standard protocol. Those samples that were negative for urinary tract infections were included in the study. On the third post-operative day (after 48 hours), at the time of removal of catheter, again urine sample was collected for culture and sensitivity. Symptoms of urinary tract infections were noted. Type of bacteria isolated and their antibiotic sensitivity pattern was observed. Asymptomatic bacteriuria was identified if women did not develop symptoms of UTI and the growth of bacteria was more than or equal to $105 \mathrm{CFU} / \mathrm{ml}$.

\section{RESULTS}

This study included 500 adult patients who received indwelling urethral Foley's catheter and urinary drainage system in wards in DR BRAM Hospital, from April 2018 to March 2019.

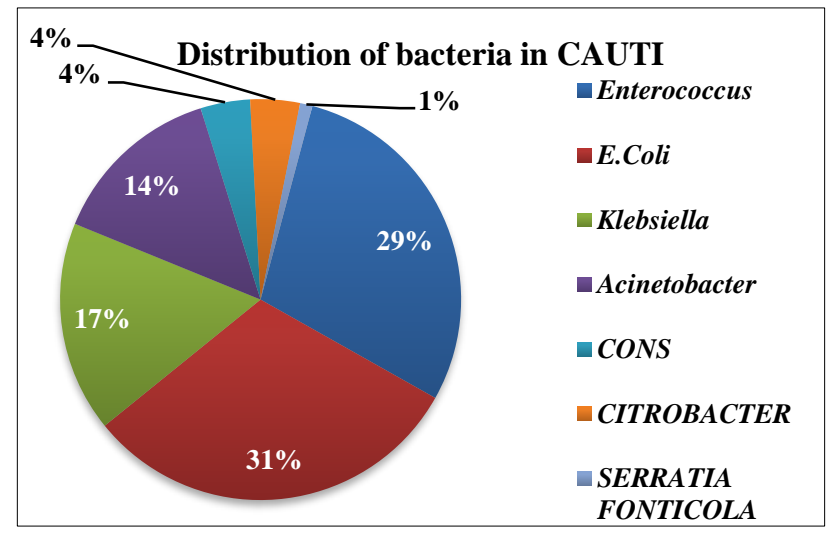

Figure 1: Percentage of bacterial distribution in CAUTI.

Overall incidence of CAUTI was $10.6 \%$. Of 500 urine samples cultured, $53(10.6 \%)$ were culture positive and $447(89.4 \%)$ showed no evidence of growth. Duration of catheterization varied from 48-72 hours. Incidence of CAUTI was directly proportional to duration of catheterization and $4 \%$ subjects developed clinical signs or symptoms of UTI after 2 calendar days from the time of insertion of indwelling urinary catheter. Monomicrobial CAUTI was obtained from 48 samples and rest was polymicrobial. The study revealed a total of 7 bacterial isolates, out of which 2 were gram positive and 5 were gram negative bacteria. Overall predominant etiological agent was Escherichia coli (31\%), followed by Enterococcus species (29\%), Klebsiella species (17\%), Acinetobacter species (14\%), coagulase-negative Staphylococcus (CoNS) species (4\%), Citrobacter species $(4 \%)$ and Serratia fonticola (1\%), as shown in Figure 1.

\section{Sensitivity pattern}

Antimicrobial sensitivity pattern of bacterial isolates is depicted in Table 1. Among Enterococcus species isolates about $16(94.1 \%)$ were sensitive to vancomycin, followed by $12(70.5 \%)$ to nitrofurantoin. Other sensitive drugs were meropenem, linezolid, amoxyclav. Among E.coli isolates, maximum $(72.2 \%)$ were sensitive to colistin, followed by meropenem, ceftazidime, cefotaxime and nitrofurantoin. Among CoNS species isolates most effective antibiotics were nitrofurantoin, linezolid, vancomycin (100\%). For Acinetobacter species, the most effective drug was colistin (87.5\%) followed by ciprofloxacin. Among Klebsiella species, maximum sensitivity was found for colistin (90\%), meropenem and ciprofloxacin. Citrobacter species showed maximum sensitivity to cefepime, ampicillin, amoxyclav, meropenem, norfloxacin, cefaperazone, nitrofurantoin, clotrimazole and colistin, 50\% each. Serratia fonticola was sensitive to amoxyclav, ciprofloxacin and cefepime-tazobactam (100\%).

\section{Resistance pattern:}

Antimicrobial resistance pattern of bacterial isolates is depicted in Table 2. Among Enterococcus species isolates, maximum was resistant to ceftriaxone (100\%), amoxycillin, ampicillin (94.4\%), norfloxacin, cefazolin, gentamycin, teicoplanin, tetracycline $(88.2 \%)$. Among $E$. coli isolates, maximum $(100 \%)$ were resistant to ceftriaxone followed by norfloxacin, amoxyclav, cefazolin, cefotaxime-clavulanate, gentamycin, ofloxacin, cefaperazone-sulbactum $(94.4 \%$ each $)$. Other resistant drugs were linezolid, imipenem, cefepime, ampicillin, clotrimazole. Among CoNS species isolates most resistance was found to ceftriaxone, norfloxacin, ofloxacin, penicillin, colistin $(100 \%)$ followed by oxacillin, gentamycin, cefoxitin. For Acinetobacter species, the most resistant drug was ceftriaxone (100\%) followed by ampicillin, cefotaxime, cefotaximeclavulanate $(87.5 \%$ each), meropenem, amoxyclav, cefazolin, cefuroxime, gentamicin, ceftriaxone, cefepimetazobactum, nitrofurantoin, teicoplanin (75\% each). Among Klebsiella species, maximum resistance was to ceftriaxone $(100 \%)$ followed by ampicillin, amoxicillin, cefazolin, amoxiclav, piptaz, ceftazidime, cefepime, cotrimoxazole, cefaperazone, cefotaxime-clavulanate (90\%). Citrobacter species showed maximum resistance to ceftriaxone $(100 \%)$ followed by ampicillin, amoxyclav, amoxicillin, cefazolin, ceftazidime, cefuroxime, imipenem, norfloxacin, nitrofurantoin, ciprofloxacin, cefixime, cefaperazone $(50 \%$ each $)$. Serratia fonticola was resistant to ampicillin, ceftriaxone, cefepime, cefuroxime, norfloxacin, colistin, cefixime. 
Table 1: Antibiotic sensitive/total isolate (\%) of uropathogens isolated.

\begin{tabular}{|c|c|c|c|c|c|c|c|}
\hline Antibiotic & Enterococcus & E. coli & Cons & Acinetobacter & Klebsiella & Citrobacter & $\begin{array}{l}\text { Serratia } \\
\text { fonticola }\end{array}$ \\
\hline Ampicillin & $1 / 17(5.8 \%)$ & $3 / 18(16.6 \%)$ & & $1 / 8(12.5 \%)$ & $1 / 10(10 \%)$ & $1 / 2(50 \%)$ & \\
\hline Amoxycillin & $1 / 17(5.8 \%)$ & & & & & $1 / 2(50)$ & \\
\hline Amoxyclav & $6 / 17(35.2 \%)$ & $1 / 18(5.5 \%)$ & & $2 / 8(25 \%)$ & $1 / 10(10 \%)$ & $1 / 2(50 \%)$ & $1 / 1(100 \%)$ \\
\hline Imipenam & & $7 / 18(38.8 \%)$ & & $3 / 8(37.5 \%)$ & $3 / 10(30 \%)$ & & \\
\hline Meropenam & $8 / 17(47.0 \%)$ & $11 / 18(61.1 \%)$ & & $2 / 8(25 \%)$ & $6 / 10(60 \%)$ & $1 / 2(50 \%)$ & \\
\hline $\begin{array}{l}\text { Piperacillin } \\
\text { tazobactum }\end{array}$ & & $6 / 18(33.3 \%)$ & & & $1 / 10(10 \%)$ & & \\
\hline Cefazolin & $2 / 17(11.7 \%)$ & $1 / 18(5.5 \%)$ & & $2 / 8(25 \%)$ & $1 / 10(10 \%)$ & & \\
\hline Cefoxitin & & & $1 / 2(50)$ & & & & \\
\hline Ceftazidime & & $9 / 18(50 \%)$ & & & $1 / 10(10 \%)$ & & \\
\hline Cefotaxime & & $8 / 18(44.4 \%)$ & & $1 / 8(12.5 \%)$ & & & \\
\hline $\begin{array}{l}\text { Cefotaxime } \\
\text { clavulate }\end{array}$ & & $1 / 18(5.5 \%)$ & & $1 / 8(12.5 \%)$ & $1 / 10(10 \%)$ & & \\
\hline Cefepime & & $4 / 18(22.2 \%)$ & & $3 / 8(37.5 \%)$ & $3 / 10(30 \%)$ & $1 / 2(50 \%)$ & \\
\hline Cefuroxime & & $9 / 18(50 \%)$ & & $2 / 8(25 \%)$ & $2 / 10(20 \%)$ & & \\
\hline $\begin{array}{l}\text { Cefaperazone } \\
\text { sulbactum }\end{array}$ & & $1 / 18(5.5 \%)$ & & & & & \\
\hline $\begin{array}{l}\text { Cefepime } \\
\text { tazobactum }\end{array}$ & & $6 / 18(33.3 \%)$ & & $2 / 8(25 \%)$ & $5 / 10(50 \%)$ & & $1 / 1(100 \%)$ \\
\hline Gentamicin & $2 / 17(11.7 \%)$ & $1 / 18(5.5 \%)$ & $1 / 2(50 \%)$ & $2 / 8(25 \%)$ & $4 / 10(40 \%)$ & & \\
\hline $\begin{array}{l}\text { High level } \\
\text { gentamicin }\end{array}$ & $3 / 17(17.6 \%)$ & & & & & & \\
\hline Amikacin & & $6 / 18(33.3 \%)$ & & $2 / 8(25 \%)$ & $2 / 10(20 \%)$ & & \\
\hline Netilmycin & & & & $2 / 8(25 \%)$ & & & \\
\hline Norfloxacin & 2/17 (11.7\%) & $1 / 18(5.5 \%)$ & & & $5 / 10(50 \%)$ & $1 / 2(50 \%)$ & \\
\hline Ofloxacin & & $1 / 18(5.5 \%)$ & & & & & \\
\hline Oxacillin & & & $1 / 2(50 \%)$ & & & & \\
\hline Teicoplanin & $2 / 17(11.7 \%)$ & & & $1 / 8(12.5 \%)$ & & & \\
\hline Cotrimazole & $1 / 17(5.8 \%)$ & $2 / 18(11.1 \%)$ & & & $1 / 10(10 \%)$ & $1 / 2(50 \%)$ & \\
\hline Nitrofurantoin & $12 / 17(70.5 \%)$ & $9 / 18(50 \%)$ & $2 / 2(100 \%)$ & $2 / 8(25 \%)$ & $4 / 10(40 \%)$ & $1 / 2(50 \%)$ & \\
\hline Doxycycline & $3 / 17(17.6 \%)$ & & $1 / 2(50 \%)$ & & & & \\
\hline Polymyxin-B & $1 / 17(5.8 \%)$ & & & $2 / 8(25 \%)$ & $1 / 10(10 \%)$ & & \\
\hline Vancomycin & $16 / 17(94.1 \%)$ & & $2 / 2(100 \%)$ & & & & \\
\hline Linezolid & $6 / 17(35.2 \%)$ & $2 / 18(11.1 \%)$ & $2 / 2(100 \%)$ & & & & \\
\hline Tetracycline & $2 / 17(11.7 \%)$ & & & & & & \\
\hline Colistin & & $13 / 18(72.2 \%)$ & & $7 / 8(87.5 \%)$ & $9 / 10(90 \%)$ & $1 / 2(50 \%)$ & \\
\hline Cefaperazone & & & & & $1 / 10(10 \%)$ & $1 / 2(50 \%)$ & \\
\hline Ciprofloxacin & $2 / 17(11.7 \%)$ & & & $4 / 8(50 \%)$ & $6 / 10(60 \%)$ & & $1 / 1(100 \%)$ \\
\hline
\end{tabular}

Table 2: Antibiotic resistant/total isolate (\%) of uropathogens isolated.

\begin{tabular}{|c|c|c|c|c|c|c|c|}
\hline Antibiotic & Enterococcus & E. coli & CoNS & Acinetobacter & Klebsiella & Citrobacter & $\begin{array}{l}\text { Serratia } \\
\text { fonticola }\end{array}$ \\
\hline Ampicillin & $16 / 17(94.1 \%)$ & $15 / 18(83.3 \%)$ & & $7 / 8(87.5 \%)$ & $9 / 10(90 \%)$ & $1 / 2(50 \%)$ & $1 / 1(100 \%)$ \\
\hline Amoxycillin & $16 / 17(94.1 \%)$ & & & & & $1 / 2(50 \%)$ & \\
\hline Amoxyclav & $11 / 17(64.7 \%)$ & $17 / 18(94.4 \%)$ & & $6 / 8(75 \%)$ & $9 / 10(90 \%)$ & $1 / 2(50 \%)$ & \\
\hline Imipenam & & $11 / 18(61.1 \%)$ & & $5 / 8(62.5 \%)$ & $7 / 10(70 \%)$ & & \\
\hline Meropenam & $9 / 17(52.9 \%)$ & $7 / 18(38.8 \%)$ & & $6 / 8(75 \%)$ & $4 / 10(40 \%)$ & $1 / 2(50 \%)$ & \\
\hline Penicillin & & & $2 / 2(100$ & & & & \\
\hline $\begin{array}{l}\text { Piperacillin } \\
\text { tazobactum }\end{array}$ & & $12 / 18(66.6 \%)$ & & & 9/10 (90\%) & & \\
\hline Cefazolin & $15 / 17(88.2 \%)$ & $17 / 18(94.4 \%)$ & & $6 / 8(75 \%)$ & $9 / 10(90 \%)$ & & \\
\hline Cefoxitin & & & $1 / 2\left(50^{c}\right.$ & & & & \\
\hline Ceftazidime & & $9 / 18(50 \%)$ & & & $9 / 10(90 \%)$ & & \\
\hline Cefotaxime & & $10 / 18(55.5 \%)$ & & $7 / 8(87.5 \%)$ & & & \\
\hline
\end{tabular}




\begin{tabular}{|c|c|c|c|c|c|c|c|}
\hline Antibiotic & Enterococcus & E. coli & CoNS & Acinetobacter & Klebsiella & Citrobacter & $\begin{array}{l}\text { Serratia } \\
\text { fonticola }\end{array}$ \\
\hline $\begin{array}{l}\text { Cefotaxime } \\
\text { clavulate }\end{array}$ & & $17 / 18(94.4 \%)$ & & $7 / 8(87.5 \%)$ & $9 / 10(90 \%)$ & & \\
\hline Cefepime & & $14 / 18(77.7 \%)$ & & $5 / 8(62.5 \%)$ & $7 / 10(70 \%)$ & & $1 / 1(100 \%)$ \\
\hline Cefuroxime & & $9 / 18(50 \%)$ & & $6 / 8(75 \%)$ & $8 / 10(80 \%)$ & & $1 / 1(100 \%)$ \\
\hline $\begin{array}{l}\text { Cefaperazone } \\
\text { sulbactum }\end{array}$ & & $17 / 18(94.4 \%)$ & & & & & \\
\hline Ceftriaxone & $17 / 17(100 \%)$ & $18 / 18(100 \%)$ & $2 / 2(100 \%)$ & $8 / 8(100 \%)$ & $10 / 10(100 \%)$ & $2 / 2(100 \%)$ & $1 / 1(100 \%)$ \\
\hline $\begin{array}{l}\text { Cefepime } \\
\text { tazobactum }\end{array}$ & & $12 / 18(66.6 \%)$ & & $6 / 8(75 \%)$ & $5 / 10(50 \%)$ & & \\
\hline Gentamicin & $15 / 17(88.2 \%)$ & $17 / 18(94.4 \%)$ & $1 / 2(50 \%)$ & $6 / 8(75 \%)$ & $6 / 10(60 \%)$ & & \\
\hline $\begin{array}{l}\text { High level } \\
\text { gentamicin }\end{array}$ & $14 / 17(82.3 \%)$ & & & & & & \\
\hline Amikacin & & $12 / 18(66.6 \%)$ & & $6 / 8(75 \%)$ & $8 / 10(80 \%)$ & & \\
\hline Tobramycin & & & & $2 / 8(25 \%)$ & & & \\
\hline Norfloxacin & $15 / 17(88.2 \%)$ & $17 / 18(94.4 \%)$ & $2 / 2(100 \%)$ & $1 / 8(12.5 \%)$ & $5 / 10(50 \%)$ & $1 / 2(50 \%)$ & $1 / 1(100 \%)$ \\
\hline Ofloxacin & & $17 / 18(94.4 \%)$ & $2 / 2(100 \%)$ & & & & \\
\hline Oxacillin & & & $1 / 2(50 \%)$ & & & & \\
\hline Teicoplanin & $15 / 17(88.2 \%)$ & & & $6 / 8(75 \%)$ & & & \\
\hline Cotrimazole & & $16 / 18(88.8 \%)$ & & $1 / 8(12.5 \%)$ & $9 / 10(90 \%)$ & & \\
\hline Nitrofurantoin & $5 / 17(29.4 \%)$ & $9 / 18(50 \%)$ & & $6 / 8(75 \%)$ & $6 / 10(60 \%)$ & $1 / 2(50 \%)$ & \\
\hline Doxycycline & $14 / 17(82.3 \%)$ & & & & & & \\
\hline Tetracycline & $15 / 17(88.2 \%)$ & & & & & & \\
\hline Ciprofloxacin & $10 / 17(58.8 \%)$ & $7 / 18(38.8 \%)$ & & $4 / 8(50 \%)$ & $4 / 10(40 \%)$ & $1 / 2(50 \%)$ & \\
\hline Colistin & & & $2 / 2(100 \%)$ & & & & $1 / 1(100 \%)$ \\
\hline Piperacillin & $2 / 17(11.7 \%)$ & $3 / 18(16.6 \%)$ & & & & & \\
\hline Linezolid & $11 / 17(64.7 \%)$ & $16 / 18(88.8 \%)$ & & & & & \\
\hline Cefixime & & $4 / 18(22.2 \%)$ & & $5 / 8(62.5 \%)$ & $6 / 10(60 \%)$ & $1 / 2(50 \%)$ & $1 / 1(100 \%)$ \\
\hline Vancomycin & $1 / 17(5.8 \%)$ & & & & & & \\
\hline Cefaperazone & & & & & $9 / 10(90 \%)$ & $1 / 2(50 \%)$ & \\
\hline Levofloxacin & & & & $1 / 8(12.5 \%)$ & $1 / 10(10 \%)$ & & \\
\hline Sulbactum & & & & $1 / 8(12.5 \%)$ & & & \\
\hline Moxifloxacin & & & & & $1 / 10(10 \%)$ & & \\
\hline
\end{tabular}

\section{DISCUSSION}

Catheter associated bacteriuria is the most widespread healthcare associated infection in developed as well as in developing countries. In this study, the overall incidence of CAUTI was $10.6 \%$. Study by Verma $S$ et al, found $15.9 \%$ incidence of CAUTI. ${ }^{3}$ Incidence of CAUTI in this study was found less than other compared studies. This could be due to overall less duration of catheterization compared to other studies. This variation could also be attributed to difference in study protocols, type of patients included, number of centers where the study was performed and duration of study.

In this study, incidence of CAUTI was directly proportional to the duration of catheterization and out of 53 culture positive CAUTI, 98\% of patients had asymptomatic UTI. In this study $91 \%$ of CAUTI are monomicrobial and most frequent pathogen responsible for CAUTI as Escherichia coli (31\%). On comparison to other studies, Raminder et al, found maximum (90\%) of CAUTI was due to E. coli. ${ }^{4} E$. coli is the most common pathogen in the presence of a catheter as well. The persistence of $E$. coli strains is related to the presence of type 1 pili, an adhesin for uroepithelium as well as the Tamm-Horsfall protein. ${ }^{5}$

Other organisms that were isolated in this study includes Enterococcus (29\%), Klebsiella species (17\%), Acinetobacter species (14\%), Coagulase negative staphylococcus aureus and Citrobacter species (4\%) and Serratia fonticola (1\%).

\section{Antibiotic susceptibility pattern of isolated gram negative uropathogens}

In this study, most of the $E$. coli were sensitive to colistin $(72.2 \%)$, meropenem $(61.1 \%)$, ceftazidime, nitrofurantoin (50\%), cefotaxime $(44.4 \%)$. On comparing with other similar studies, one study by Gupta et al, found similar results to that of this study that is, most sensitive antibiotics for gram negative isolates were colistin followed by tigecycline, ciprofloxacin, imipenem. ${ }^{6}$ 
In this study, among other gram-negative bacteria, most Acinetobacter species were sensitive colistin (87.5\%). Among Klebsiella species, maximum sensitivity was found for colistin $(90 \%)$, meropenem and ciprofloxacin. For Citrobacter species, maximum sensitivity was to cefepime, ampicillin, amoxyclav, meropenem, norfloxacin, cefaperazone, cotrimazole and colistin $50 \%$ each. Serratia fonticola was sensitive to amoxyclav, ciprofloxacin and cefepime- tazobactam (100\%).

This study shows that, $55.5 \%$ isolates of $E$. coli were resistant to cefotaxime, $50 \%$ to cefuroxime, $100 \%$ to ceftriaxone and $50 \%$ to ceftazidime. This higher resistance to cephalosporins can also be on compared with studies. ${ }^{3,6-8}$ Among other organisms, in this study $80 \%$ of Klebsiella species, $75 \%$ of Acinetobacter species and $100 \%$ Serratia fonticola was resistant to cefuroxime. $90 \%$ of Klebsiella species were resistant to ceftazidime.

High resistance rates to ciprofloxacin - a fluoroquinolone considered highly effective in the treatment of CAUTIs was another finding of this study. In this study $38.8 \%$ of E. coli isolates, $50 \%$ of Citrobacter and Acinetobacter species isolates and $40 \%$ of Klebsiella species isolates were resistant to ciprofloxacin. Similar study found $88.89 \%$ of gram-negative bacteria resistant to ciprofloxacin. ${ }^{4}$ Another study found $77.7 \%$ resistant Enterobacteriaceae to ciprofloxacin. ${ }^{5}$ Norfloxacin is another fluoroquinolone, to which $94.4 \%$ of E. coli, $50 \%$ of Klebsiella and Citrobacter species, $12.5 \%$ of Acinetobacter species were resistant. This is in accordance with Bhani et al, where CAUTIs due to gramnegative bacteria were significantly resistant to norfloxacin $(81.25 \%){ }^{9}$ Cotrimoxazole is another commonly used drug. In present study $88.8 \%$ of E. coli, $90 \%$ of Klebsiella species, $12.5 \%$ of Acinetobacter species were resistant to cotrimazole. Two other similar studies have got similar results, that is about $88.9 \%$ of Enterobacteriaceae isolates resistant to Cotrimoxazole. . $^{3,4}$

In this study $58.33 \%$ of Enterobacteriaceae were resistant to nitrofurantoin, another commonly used drug for treatment of catheter associated urinary tract infections.

High incidence of Carbapenem resistance in the isolates was obtained in present study. $61.1 \%$ of E. coli, $62.5 \%$ of Acinetobacter species and $70 \%$ of Klebsiella species were resistant to imipenam. $38.8 \%$ of E. coli, $75 \%$ of Acinetobacter species, $40 \%$ of Klebsiella species and $50 \%$ of Citrobacter species were resistant to meropenem.

Aminoglycoside resistance among the organisms isolated was also observed in this study; with $94.4 \%$ E. coli were resistant to gentamycin. $66.6 \%$ of $E$. coli, $75 \%$ Acinetobacter species, $80 \%$ of Klebsiella species were resistant to amikacin. Similar study showed $33.3 \%$ of Enterobacteriaceae isolates being resistant to both gentamicin and amikacin. ${ }^{3}$
In this study $94.4 \%$ of E. coli, $90 \%$ of Klebsiella species, $75 \%$ of Acinetobacter species and $50 \%$ of Citrobacter species were resistant to amoxyclav. Mishra et al, found $100 \%$ of $E$. coli showing amoxyclav resistance. ${ }^{6}$

\section{Antibiotic susceptibility pattern of isolated gram positive uropathogens}

In this study, gram-positive bacteria- Enterococcus species were sensitive to vancomycin $(94.1 \%)$, followed by nitrofurantoin $(70.5 \%)$ and they were resistant to ceftriaxone (100\%), amoxycillin, ampicillin (94.4\%), norfloxacin, cefazolin, gentamycin, teicoplanin, tetracycline $(88.2 \%)$. CoNS showed $100 \%$ sensitivity to vancomycin, nitrofurantoin and linezolid and maximum resistance to ceftriaxone, norfloxacin, ofloxacin and colistin.

Another study shows that gram positive organisms were sensitive to vancomycin which is similar finding of this study. ${ }^{6}$ They also have shown maximum sensitivity of these organisms to linezolid which contrasts with this study as about $64.7 \%$ of Enterococci were resistant to linezolid. They have also found resistance of grampositive organisms to ciprofloxacin. ${ }^{6}$

\section{CONCLUSION}

The empirical use of antibiotics must be avoided, and antibiotics must be used only after susceptibility testing. This will help in selection of the appropriate antibiotic for therapeutic use, prevent indiscriminate, irrational use of antibiotics and its resistance. This will also improve the cost efficiency and decrease the duration of hospital stay. Implementation of infection control practices must be strictly done and followed for prevention and control of CAUTI.

\section{Funding: No funding sources \\ Conflict of interest: None declared}

Ethical approval: The study was approved by the Institutional Ethics Committee

\section{REFERENCES}

1. Centre for diseases control, device associated module, 2019. Available at: https://www.cdc.gov/nhsn/pdfs/pscmanual/pcsmanua 1_current.pdf. Accessed on $22^{\text {nd }}$ May 2020.

2. Leelakrishna P, Karthik Rao B. A study of risk factors for catheter associated urinary tract infection. Int J Adv Med. 2018;5(2):334-9.

3. Verma S, Naik SA, Deepak TS. Etiology and risk factors of catheter associated urinary tract infections in ICU patients. Int $\mathrm{J}$ Med Microbiol Trop Dis. 2017;3(2):65-70.

4. Sandhu R, Sayal P, Jakkhar R, Sharma G. Catheterization-associated urinary tract infections: Epidemiology and incidence from tertiary care 
hospital in Haryana. J Health Res Rev. 2018;5:13541.

5. Tenke P, Mezei T, Bőde I, Köves B. Catheterassociated urinary tract infections. Euro Urol Suppl. 2017;16(4):138-14.

6. Mishra D, Bhaskara Rao K, Catheter associated urinary tract infection in an acute care setting of a tertiary care centre in South India. Int J Res Med Sci. 2019;7(6):2182-6.

7. Mangukiya JD, Patel KD, Vegad MM. Study of incidence and risk factors of urinary tract Infections in catheterized Patients admitted at tertiary care hospital. Int. J of Res Med Sci. 2015;3(12):3808-11.

8. Gupta T, Prem MP, Ved P, Agarwal P, Premi HK, Kumar A. Spectrum of catheter associated urinary tract infections in the obstetric patients in a tertiary care hospital. Int $\mathrm{J}$ Contemp Med Res. 2016;3(11):3349-52.

9. Bhani D, Bachhiwal R, Sharma R, Maheshwari RK. Microbial profile and antimicrobial susceptibility pattern of uropathogens isolated from catheter associated urinary tract infection (CAUTI). Int J Curr Microbiol Appl Sci. 2017;6:2446-53.

Cite this article as: Singh A, Kujur A,

Muthulakshmi M, Daharwal A. The study of antibiotic-sensitivity and resistance pattern of bacteria causing catheter associated urinary tract infection. Int J Reprod Contracept Obstet Gynecol 